\title{
Case Study- Validation of Temperature Sources
}

\author{
Vinay Rajput \\ Scientist ' $C$ ' \\ Electronics Test \& Development Centre \\ STQC Directorate, Deptt. of Electronics \& IT \\ Mohali, Punjab-160 071 (India)
}

\begin{abstract}
Temperature source is used to evaluate the measurement capabilities of different resistance temperature detector (RTD) sensors, thermocouples and thermometers. In this paper, need of validation for different temperature sources is investigated using comparison method. The smaller value of uncertainty gives the confidence in measurements. Temperature sources like Dry block calibrator, Oil/water bath and Furnaces for measurements are implemented for this work. The stability \& uniformity under different load conditions are considered, for the evaluation of uncertainty.
\end{abstract}

\section{INTRODUCTION (CONSIDERATIONS IN USING TEMPERATURE SOURCES)}

The calibration laboratories and pharmaceutical industries have highly regulated environment based on research, calibration, record keeping and validation. The term "Thermal Validation" is the process of qualifying or validating the equipment and its storage facilities, to prove that they will maintain the temperature they are designed for.

Validation $^{1}$ verifies the system/equipment under the extreme working conditions during the process, to prove that system performance remains unaffected. It is a documented act, which provides a high degree of assurance about any procedure/process/equipment or system that actually lead to expected results. The validity of system/equipment can be established by prospective, concurrent and retrospective studies.

To execute the validation program, following methodology is used as depicted in Fig.

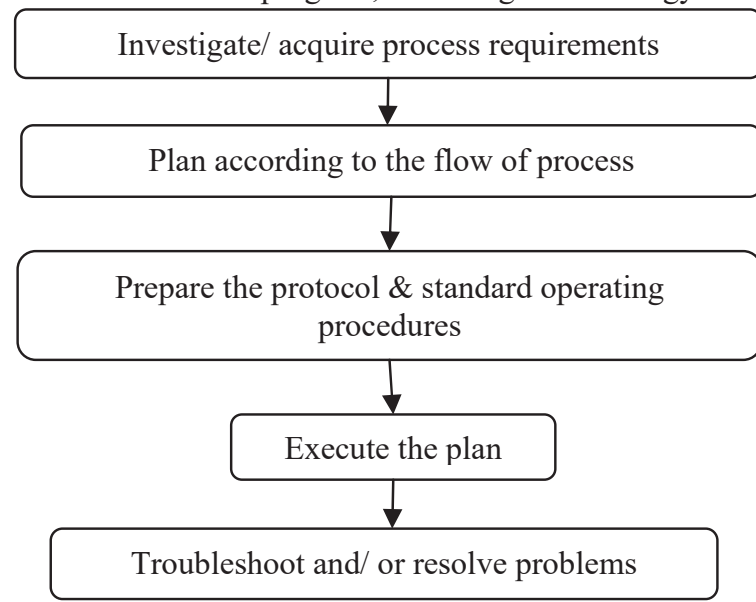

Types of Process validation

- Experimental approach- In Prospective Validation, conducted prior to the distribution of either a new product or a product made under a modified process, where the modifications are significant and may affect the product's characteristics and in Concurrent Validation, it gives assurance regarding consistency of quality from batch to batch.

- Analysis of Historical Data- Retrospective validation is based on extensive data accumulated over use at several times under different loading conditions.

- Revalidation- Repetition of validation process or a specific problem of it, to ensure continued compliance with established requirements. It is required after modification, relocation or repair of system.

Stages of Validation2 
Validation of system/ equipment may be divided into three segments-

i) Installation Qualification (IQ)

- Verifies all the identification information/ parameter, location, utility requirements and safety feature of equipments as per manufacturer's recommendations.

- Verify the condensing/ heating unit pipeline along with accessories, evaporators \& control system.

- Check all the electrical connections.

- Can the required temperature be attained or not?

ii) Operational Qualification (OQ)

- Check the required temperature in proper range, by temperature mapping and defrost cycle, using the calibrated thermometer or temperature sensors.

- Test Cycles- Define the process period, required temperature for the process and rate of rise for temperature increase $\left({ }^{\circ} \mathrm{C} /\right.$ minute $)$ and fall time.

- Test alarms

\section{iii) Performance Qualification (PQ)}

- Described the procedure for demonstrating that the system can consistently perform and meet required specifications under routine operations and where appropriate, under extreme working conditions.

- Temperature mapping under full load conditions.

- Concurrent validation- daily monitoring of temperature.

Stabilisation

To validate the temperature source, system should be stabilized in term of uniformity as well as stability and data

shall be repeatable \& reproducible-

Repeatability ${ }^{6}$

Closeness of the agreement between the results of successive measurements of the same measurand carried out using same method on identical test items in the same laboratory, by the same operator, using the same equipment within short interval of time.

Reproducible ${ }^{6}$

Closeness of the agreement between the results of the measurements of the same measurand carried out using the same method on identical test items in different laboratories with different operators using different equipment

Uniformity

To evaluate the uniformity of the temperature source, two reference sensors of same accuracy may be used in different location and observe the temperature difference $(\delta \mathrm{T} 1)$ at required temperature. Again observe the temperature difference $(\delta \mathrm{T} 2)$ at same temperature, after interchange the location of same sensors. To calculate the uniformity, following should be used-

$$
\text { Uniformity }=\left[\left(\delta T_{1}\right)-\left(\delta T_{2}\right)\right] / 2
$$

Stability

Stability of temperature source is study of temperature attained in system over time. After achieve the required temperature- in variation of time, temperature should be same.

To evaluate the stability of the temperature source- after achieved the required temperature start to take observation after each 05 minute and minimum for half hour.

Example - Assume that range of temperature source is $0^{\circ} \mathrm{C}$ to $150^{\circ} \mathrm{C}$, we will take the observation at mimimum, maximum and mid of temperature range to evaluate the stability of entire range. We will start to take the observation after each 5 minute for duration of minimum half hours e.g. $T_{5}, T_{10}, T_{15}, T_{20}, T_{25}, T_{30}$ and calculate the maximum deviation in observations.

Stability at max. temp. (i.e. $\left.150^{\circ} \mathrm{C}\right)=$

(maximum deviation in $\mathrm{T}_{5}, \mathrm{~T}_{10}, \mathrm{~T}_{15}, \mathrm{~T}_{20}, \mathrm{~T}_{25}, \mathrm{~T}_{30}$ )/ $2=\boldsymbol{\delta} \mathbf{T}_{\mathbf{H}}$ 
Stability at min. temp. (i.e. $\left.0^{\circ} \mathrm{C}\right)=$

(maximum deviation in $\mathrm{T}_{5}, \mathrm{~T}_{10}, \mathrm{~T}_{15}, \mathrm{~T}_{20}, \mathrm{~T}_{25}, \mathrm{~T}_{30}$ )/ $2=\boldsymbol{\delta} \mathbf{T}_{\mathbf{L}}$

Stability at mid temp. (i.e. $\left.75^{\circ} \mathrm{C}\right)=$

(maximum deviation in $\mathrm{T}_{5}, \mathrm{~T}_{10}, \mathrm{~T}_{15}, \mathrm{~T}_{20}, \mathrm{~T}_{25}, \mathrm{~T}_{30}$ )/ $2=\boldsymbol{\delta} \mathbf{T}_{\mathbf{M}}$

Stability of entire range will be highest value of deviation $\delta \mathrm{T}_{\mathrm{H}} / \delta \mathrm{T}_{\mathrm{M}} / \delta \mathrm{T}_{\mathrm{L}}$.

Case study of validation for Dry Block Calibrator (Temperature Source)

This case study is based upon the observations on a temperature source- Dry Block Calibrator using 05 holes, which have the range $(-) 55^{\circ} \mathrm{C}$ from ambient to $(+) 140^{\circ} \mathrm{C}$, Stability $0.03^{\circ} \mathrm{C}$, Accuracy $\pm 0.2^{\circ} \mathrm{C}$.

Installation Qualification

- $\quad$ Electrical mains supply voltage should be $220 \mathrm{~V} \pm 10 \mathrm{~V}$.

- $\quad$ Item should be operating under controlled environmental conditions.

Operational Qualification

- $\quad$ Required Temperature is $121^{\circ} \mathrm{C}$

- $\quad$ Temperature cycle- From ambient to $121^{\circ} \mathrm{C}$ within $01 \mathrm{Hrs}$.

- At $121^{\circ} \mathrm{C}$ for minimum 45 minutes

- From $121^{\circ} \mathrm{C}$ to ambient

- $\quad$ Check the temperature source using the Semi Standard Platinum Resistance Thermometer (S.P.R.T.) and Multifunction Process Calibrator.

- $\quad$ Observations of standard equipments and temperature source is -

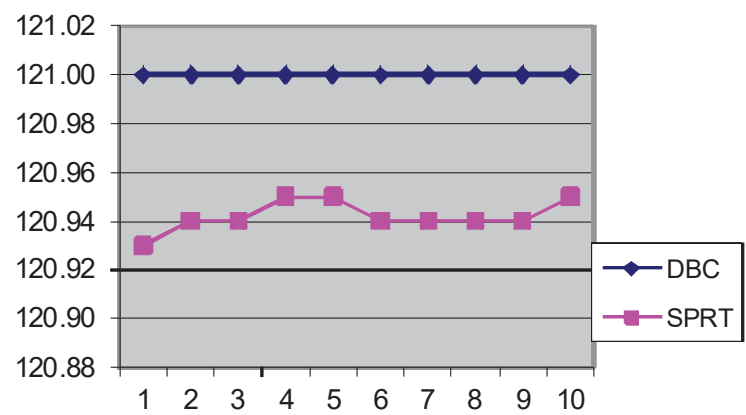

Performance Qualification

- $\quad$ Pre Test- Standard equipments (SPRT \& Process Calibrator) initially verified using the higher standards before start the validation.

- $\quad$ Observe the temperature $121^{\circ} \mathrm{C}$ at different possible load conditions -

NO-LOAD Conditions

Apply only S.P.R.T. to observe the temperature in metal insert of D.B.C. Observations of standard equipments and temperature source is -

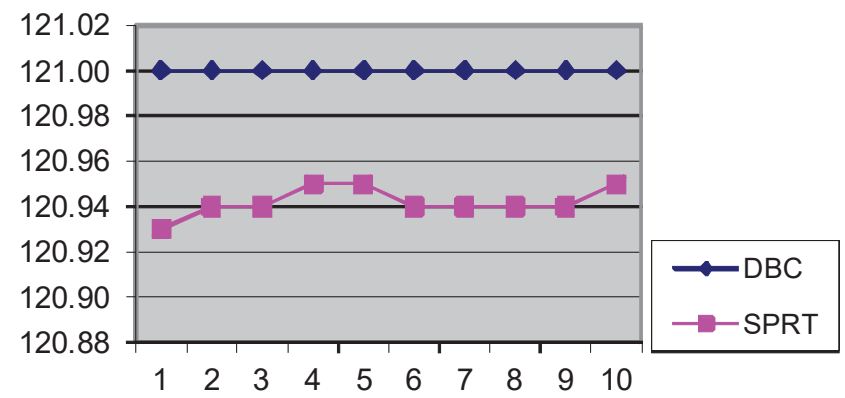


Results: Temperature displayed at temperature source is $121.0^{\circ} \mathrm{C}$ and at standard equipments is $120.94^{\circ} \mathrm{C}$, where standard deviation is $0.008^{\circ} \mathrm{C}$ and expanded uncertainty ${ }^{6}$ at $95 \%$ C.L. $\pm 0.103^{\circ} \mathrm{C}$

HALF-LOAD Conditions

Apply same S.P.R.T. to observe the temperature \& 02 no. additional sensors of different immersion length \& dia in metal insert of D.B.C.

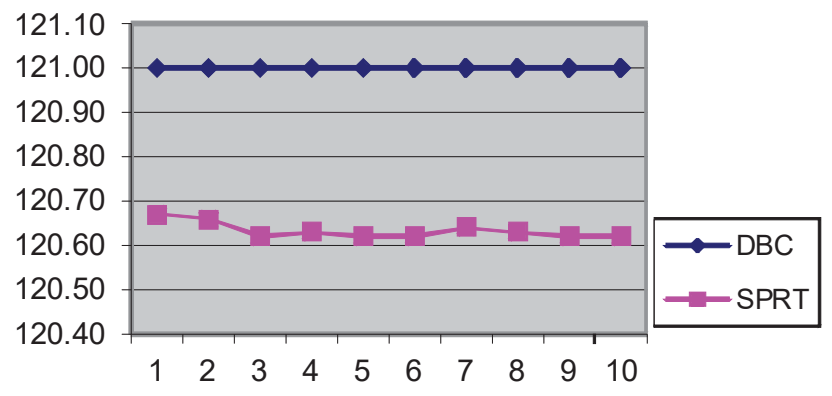

Results: Temperature displayed at temperature source is $121.0^{\circ} \mathrm{C}$ and at standard equipments is $120.63^{\circ} \mathrm{C}$, where standard deviation is $0.016^{\circ} \mathrm{C}$ and expanded uncertainty ${ }^{6}$ at $95 \%$ C.L. $\pm 0.104^{\circ} \mathrm{C}$

FULL-LOAD Conditions

Apply same S.P.R.T. to observe the temperature \& 04 no. additional sensors of different immersion length \& dia in metal insert of D.B.C.

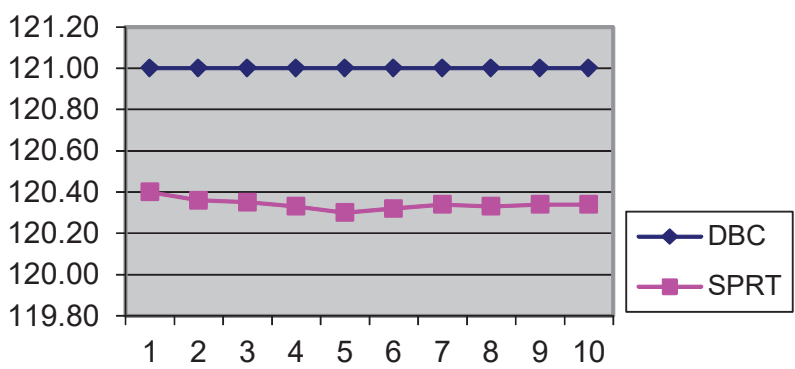

Results: Temperature displayed at temperature source is $121.0^{\circ} \mathrm{C}$ and at standard equipments is $120.34^{\circ} \mathrm{C}$, where standard deviation is $0.025^{\circ} \mathrm{C}$ and expanded uncertainty 6 at $95 \%$ C.L. $\pm 0.104^{\circ} \mathrm{C}$

\section{CONCLUSION}

Variation of temperature attained by temperature source at different load conditions under same environmental conditions and using same measuring standards is shown below, where all standard equipments used for observations are with valid calibration and traceable to national standard-

\begin{tabular}{|c|c|c|c|}
\hline $\begin{array}{c}\text { Display } \\
\text { at } \\
\text { DBC }\end{array}$ & $\begin{array}{c}\text { Observations } \\
\text { at No-Load } \\
\text { Conditions }\end{array}$ & $\begin{array}{c}\text { Observations } \\
\text { at Half-Load } \\
\text { Conditions }\end{array}$ & $\begin{array}{c}\text { Observations } \\
\text { at Full-Load } \\
\text { Conditions }\end{array}$ \\
\hline \multirow{2}{*}{$121.0^{\circ} \mathrm{C}$} & $120.94 \pm$ & $120.63 \pm$ & $120.34 \pm$ \\
& $0.103^{\circ} \mathrm{C}$ & $0.104^{\circ} \mathrm{C}$ & $0.104^{\circ} \mathrm{C}$ \\
\hline
\end{tabular}

Additional standard sensors shall be use to observe the actual temperature in dry block type temperature sources because actual temperature attained by the metal insert of temperature source (Dry Block Calibrator) depends on the physical dimensions (dia \& immersion length) of sensors \& no. of sensors inserted in the metal block.

\section{ACKNOWLEDGMENT}

I would like to offer my thanks to the Ms. Ravinder Sahi, Senior Director, ETDC for extending their help to explore the technical knowledge and without whom it wouldn't be possible to get this done. 


\section{REFERENCES}

[1] Good manufacturing requirements-Part-2: Validation

[2] Guidelines on General Principles of Process Validation by U.S. Food \& Drug Administration AGB Scientific details

[3] Journal on Validation Technology

[4] WHO Guidelines- 13

[5] Guidelines for Estimation and Expression of Uncertainty in Measurement (NABL-141) 